\title{
The Involvement of Genes in Adolescent Depression: A Systematic Review
}

\author{
Liangwei Xia ${ }^{1}$ and Shuqiao Yao ${ }^{1,2 *}$ \\ ${ }^{1}$ Medical Psychological Institute, Second Xiangya Hospital, Central South University, Changsha, Hunan, China, ${ }^{2}$ National \\ Technology Institute of Psychiatry, Changsha, Hunan, China
}

\section{OPEN ACCESS}

Edited by:

Morten L. Kringelbach, University of Oxford, UK; University of Aarhus, Denmark

Reviewed by:

Heather Trantham-Davidson, Medical University of South Carolina,

USA

Fiona Hollis,

École Polytechnique Fédérale de Lausanne, Switzerland

${ }^{*}$ Correspondence:

Shuqiao Yao shuqiaoyao@163.com

Received: 17 July 2015 Accepted: 14 November 2015 Published: 21 December 2015

Citation:

Xia $L$ and Yao S (2015) The Involvement of Genes in Adolescent Depression: A Systematic Review. Front. Behav. Neurosci. 9:329. doi: 10.3389/fnbeh.2015.00329
Numerous studies have reported on the roles of genetic factors in the development of depression in adolescents and young adults. However, there are few systematic reviews that update our understanding of adolescent depression with the biological findings identifying the roles of gene expression and/or polymorphism(s). This review systematically summarized the findings that clearly identified the contribution of a gene to the risk of depression in adolescents between the ages of 10 and 19 years old and young adults between the ages of 20 and 25 years old. Data were obtained through searching PubMed, Embase, and Web of Science. A total of 47 studies on early adolescence and three studies on young adults were included in the current review. Most articles studied genes in the serotonergic system $(n=26)$, dopaminergic system $(n=3)$, and the Brain-derived neurotropic factor (BDNF) gene $(n=12) .92 .3 \%$ of studies $(24 / 26)$ identified positive associations of 5-HTTLPR polymorphism with depressive illness or depressive symptoms. 83.3\% of studies (10/12) found positive association between $B D N F$ Val66Met genotype and adolescent depressive symptoms. More studies should be conducted on the 18 genes reported in a few studies to clarify their roles in the risk for adolescent depression.

Keywords: adolescent, depression, gene, genetics, polymorphism, single nucleotide

\section{INTRODUCTION}

Depression is a common disorder affecting an estimated 350 million people worldwide. Longlasting depression with moderate or severe intensity is a serious medical condition that can lead to suicide. An estimated 1 million deaths each year are related to suicide. Although treatments for depression are effective, fewer than half of all individuals with depression around the world (in some countries, fewer than 10\%) take anti-depressants (WHO, 2014a). Barriers to effective care include a lack of resources, a lack of trained health care providers, and social stigma associated with mental disorders (WHO EMRO, 2014). Inaccurate assessment and incorrect diagnosis of depression in its early stages can also prevent the effective care of individuals with depression. It is commonly believed that depression is a result of the complex interaction of social, psychological, and biological factors. Numerous studies have reported the involvement of abnormal gene expression or single nucleotide polymorphisms (SNPs) of genes in the development of depression (Bufalino et al., 2013).

Depression is also the leading cause of disability in young people worldwide. An estimated nine percent of children and adolescents in the US are affected by depression (Dunn et al., 2011). Although the diagnostic criteria for children and adolescent depression are no different from those 
for adults, one epidemiological study showed that there are different risk factors for the onset of depression in young people and in adults (Jaffee et al., 2002). For example, depressive adolescents experienced more perinatal insults, caretaker instability, and criminality than adult-onset depressive patients. Also, depressive adolescents have more behavioral and socioemotional problems than the adult-onset patients. In contrast, the adult-onset patients experienced more sexual abuse in their childhood than depressive adolescents (Jaffee et al., 2002).

Moreover, studies in neuroscience have demonstrated that adolescence is a special period of development characterized by significant changes in the structure and connectivity of the brain, as well as changes in cognition and behavior (Cousins and Goodyer, 2015). These neurological changes may interplay between genes and the environment (Paus, 2013). Results from several family and twin studies suggest that etiologic genetics do exist in depression during adolescence (Rice, 2009). A few reviews or meta-analyses have also summarized the gene $\times$ environment interaction in adolescents with depression (Franić et al., 2010; Rice, 2010; Dunn et al., 2011). However, the age range for adolescence was not accurately defined. Heterogeneity within a group of depressive patients may be problematic for the development of theory, research, and treatment of depressive patients (Jaffee et al., 2002). It is therefore necessary to summarize the findings in adolescents with an accurately defined age range: (1) to update the findings on gene expression or polymorphism in adolescent depression and (2) to evaluate the value of all genes as a biomarker of adolescent depression. The WHO defines adolescence as having an age range of 10-19 years old and as a dynamic period with biological, social, and psychological changes (WHO, 2014b). In this study, the age range of 10-19 years was defined as adolescence while an age range of 20-25 years was defined as young adult for analysis.

The goal of the current review is to systematically analyze studies that tested the role of a gene in the development of depression or as a risk factor of depression in adolescents. We focused specifically on the findings and ultimately provide substantive conclusions on which gene expression or polymorphism could be a biomarker of depression in adolescents.

\section{METHODS}

\section{Eligibility Criteria}

A systematic review of original studies on gene expression or genetic polymorphisms in adolescents with depression was conducted. Reports on gene expression or polymorphisms measured in peripheral blood or postmortem studies in adolescents were eligible for review. A study was included in the analysis when: (1) adolescents with depression or depressive symptoms fell into the range of 10-19 years old (WHO, 2014b) or young adult at an age of 20-25 years and (2) original research with the age range and gene being clearly identified. Studies were excluded if: (1) a study had subjects with age not in the two age ranges; (2) a study only provided a mean age; (3) A study contained anxious adolescents only; (4) studies that were conducted in animals or in vitro; or (5) review or studies that were not written in English.

\section{Information Sources}

Studies were pulled from the electronic databases of PubMed, Embase, and Web of Science.

\section{Search Strategy}

The primary search strategy was carried out using both the keywords and test words: "depression" and "adolescent" and "gene"; "depression" and "adolescent" and "polymorphism"; "depression" and "adolescent" and "genetics"; "depression" and "adolescent" and "genetic variants"; and "depression" and "adolescent" and "genotype".

\section{Data Collection Process}

The abstract of each study was screened and the full-text articles of potentially relevant studies were then retrieved and assessed. Data were extracted from the retrieved papers by two authors (LX and SY) independently. Disagreements were resolved by discussion in a meeting that included several experts from within the Department. The study selection process was presented in a flow diagram (Figure 1).

\section{Data Items}

Data on age range, study design, demographic characteristics of patients, and control individuals, gene expression or polymorphism, tissue type, and the results were extracted.

\section{Outcomes}

The association of gene expression or polymorphisms with disease risk, severity of depressive symptoms, and treatment outcomes.

\section{Risk of Bias in Individual Studies}

Risk of bias was assessed by evaluating choice of study design, selection of study population, allocation of control individuals, and quality of assay used.

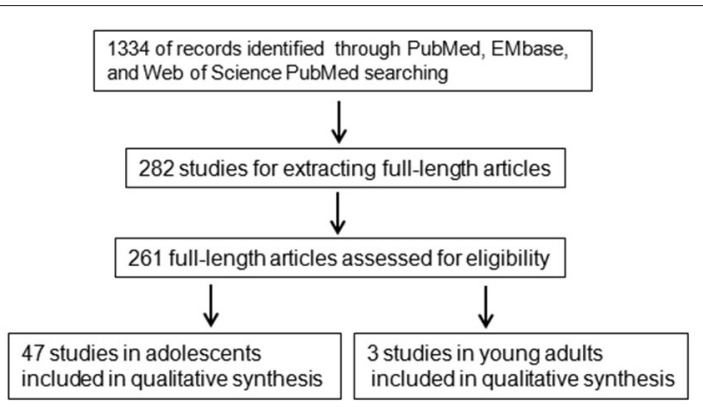

FIGURE 1 | A flowchart of literature search strategy. A flowchart of the inclusions and exclusions of studies in the current study. 


\section{Data Synthesis}

Data was summarized for each gene including the main outcomes or conclusion, positive and negative association with depression.

\section{RESULTS}

The literature search identified 1334 articles from PubMed, EMbase, and Web of Science using the keywords mentioned above after the removal of duplicates. The end date for the search is August 29, 2015. The abstracts of the 1334 articles were screened one by one and articles not written in English, review articles not for depression in adolescents, comments, and articles for animal or in vitro studies were excluded from this study. The studies where the gene name could not be identified in the abstract were also excluded from further analysis. A total of 282 studies were finally used for extracting full-length articles. However, only 261 full-length articles were downloaded for careful identification. Full-length articles of screening studies, studies in non-adolescents or with a mixed sample with the age beyond the range of 10-19 years for adolescents or 20-25 years for young adults, studies with only the mean age, studies without clearly identified gene expression or polymorphism, or others was excluded from the analysis. Finally, 47 full-length articles (Eley et al., 2004; Mamalakis et al., 2004; Burcescu et al., 2005; Miraglia del Giudice et al., 2006; Sjöberg et al., 2006; Geng et al., 2007; Hilt et al., 2007; Pandey et al., 2007, 2012; Feng et al., 2008; Aslund et al., 2009; Duncan et al., 2009; Goodyer et al., 2009, 2010; Guo and Tillman, 2009; Laucht et al., 2009; Nilsson et al., 2009; Nobile et al., 2009; Benjet et al., 2010; Brent et al., 2010; Mata et al., 2010; Nederhof et al., 2010; Uddin et al., 2010, 2011; Bouma et al., 2011; Hankin et al., 2011; Jenness et al., 2011; Mata and Gotlib, 2011; Thompson et al., 2011; Chen et al., 2012, 2013; Petersen et al., 2012; Buchmann et al., 2013; Bobadilla et al., 2013; Comasco et al., 2013; Cutuli et al., 2013; Kohen et al., 2013; Otten and Engels, 2013; Oppenheimer et al., 2013; Priess-Groben and Hyde, 2013; Stavrakakis et al., 2013; Banducci et al., 2014; Cicchetti and Rogosch, 2014; Cruz-Fuentes et al., 2014; Little et al., 2014; Zhang et al., 2015) in adolescents and three studies (Hammen et al., 2010; Starr et al., 2013; Thompson et al., 2014) in young adults were included in this study (Figure 1). The 47 studies in adolescence included 20 genes or gene families while the three studies in young adults included three genes (Table 1).

Among the studies in early adolescence, only three articles reported the association between gene expression and depression in adolescents (Mamalakis et al., 2004; Pandey et al., 2007, 2012) and one study reported a linkage analysis (Feng et al., 2008). 91.5\% (43/47) of articles reported the results of nucleotide polymorphism analysis of a gene in adolescents with depressive disease or depressive symptoms (Table 1). Most studies were related to neurotransmitter receptors and their associated metabolic enzymes, including the dopaminergic system $(D R D 2$, $D R D 4$, and COMT) and serotonergic system (serotonin 2A, 5-HTT, MAOA, and TPH). 5-HTT (5-HTTLPR polymorphism) is the most frequently examined gene (26 articles) followed by Brain-derived neurotropic factor (BNDF; 12 articles). Thirteen genes were only reported in one article. Seven genes
(COMT, serotonin 2A, MAOA, estrogen receptor $\alpha$ and $\beta, A R$, glucocorticoid receptor, and adipose polyunsaturated fatty acid gene) showed no association with depression in adolescents. Four genes (DRD2, DRD4, TPH1/2, and CREB/CREB1) were reported by two or three articles with inconsistencies. The 26 studies on 5-HTTLPR contained a total of 14,616 samples, and the 12 studies on BDNF contained a total of 7646 samples.

Approximately $92.3 \%(24 / 26)$ of studies for the association between 5-HTTLPR polymorphism and depression in adolescents yielded a positive outcome (Table 2). Among the 26 studies for 5-HTTLPR polymorphism, 22 studies analyzed the association between polymorphism and depressive symptoms (two studies showed negative findings), while four studies analyzed the role of 5-HTTLPR polymorphism in depression. Only one study analyzed the association between 5-HTTLPR polymorphism and the severity of depressive symptoms. It appears that 5-HTTLPR polymorphism is associated with both the risk and severity of depression in adolescents. There was no study to compare the role of 5-HTTLPR polymorphism in anxiety and depression. The association between 5-HTTLPR polymorphism and different types of depression (i.e., anxiety vs. irritability vs. cognitive dysfunction) was not analyzed in this study because only a few studies analyzed the association between 5-HTTLPR polymorphism and the cognitive dysfunction and the irritability.

$B D N F$ was the second most frequently studied gene in adolescents. All 12 studies analyzed the association between $B D N F$ Val66Met genotype/gene plasticity index and depressive symptoms. Among them, one study investigated the BDNF gene plasticity index in adolescents with depressive symptoms without observing any association. Eleven studies (Hilt et al., 2007; Duncan et al., 2009; Goodyer et al., 2010; Mata et al., 2010; Chen et al., 2012, 2013; Buchmann et al., 2013; Comasco et al., 2013; Stavrakakis et al., 2013; Cicchetti and Rogosch, 2014; CruzFuentes et al., 2014) investigated the association between the $B D N F$ Val66Met genotype and adolescent depressive symptoms with only one study showing no association (Nederhof et al., 2010; Table 3). However, no study analyzed the association between BDNF Val66Met genotype and severity of depressive symptoms. No study compared the role of BDNF Val66Met genotype in anxiety and depression. The association between $B D N F$ Val66Met genotype and different types of depression was not analyzed in this study because no studies analyzed the $B D N F$ Val66Met genotypes and irritability. Only one study investigated the association of BDNF Val66Met genotypes with cognitive dysfunction. Two studies reported the association of genetic variants in the dopaminergic system with adolescent depression (Bobadilla et al., 2013; Stavrakakis et al., 2013; Table 3).

Only three studies investigated the gene polymorphism and the risk of depression in young adults at an age range of 20-25 years. Thompson et al. (2014) study found that OXTR (oxytocin receptor gene) polymorphism influences the development of depressive symptoms. Starr et al. (2013) study showed that 5-HTTLPR S-allele can predict relative increases in probability of depression among boys. Hammen et al. (2010) study revealed that chronic family stress at age 15 predicted 
TABLE 1 | Summary of literature and outcomes in adolescents.

\begin{tabular}{|c|c|c|c|}
\hline Gene & Reference & Measurement & $\begin{array}{l}\text { Association with } \\
\text { depression }\end{array}$ \\
\hline DRD2 & $\begin{array}{l}\text { Guo and Tillman (2009), Stavrakakis et al. (2013) and } \\
\text { Zhang et al. (2015) }\end{array}$ & Polymorphism & $1 \mathrm{no} / 2$ yes \\
\hline DRD4 & $\begin{array}{l}\text { Guo and Tillman (2009), Bobadilla et al. (2013) and } \\
\text { Stavrakakis et al. (2013) }\end{array}$ & Polymorphism & 1 no/2 yes \\
\hline Catechol-O-methyltransferase (COMT) & Stavrakakis et al. (2013) & Polymorphism & no \\
\hline Serotonin $2 \mathrm{~A}$ & Stavrakakis et al. (2013) & Polymorphism & no \\
\hline Monoamine oxidase A (MAOA) & Eley et al. (2004) and Stavrakakis et al. (2013) & Polymorphism & no \\
\hline Tryptophan hydroxylase gene (TPH1/2) & $\begin{array}{l}\text { Nobile et al. (2009), Stavrakakis et al. (2013) and Eley } \\
\text { et al. (2004) }\end{array}$ & Polymorphism & 1 no/2 yes \\
\hline Serotonin transporter gene $(5-\mathrm{HTT})$ & $\begin{array}{l}\text { Eley et al. (2004), Sjöberg et al. (2006), Aslund et al. } \\
\text { (2009), Goodyer et al. (2009, 2010), Laucht et al. } \\
\text { (2009), Nobile et al. (2009), Benjet et al. (2010), Uddin } \\
\text { et al. (2010, 2011), Hankin et al. (2011), Jenness et al. } \\
\text { (2011), Mata and Gotlib (2011), Petersen et al. (2012), } \\
\text { Buchmann et al. (2013), Comasco et al. (2013), Cutuli } \\
\text { et al. (2013), Kohen et al. (2013), Oppenheimer et al. } \\
\text { (2013), Otten and Engels (2013), Priess-Groben and } \\
\text { Hyde (2013), Stavrakakis et al. (2013), Banducci et al. } \\
\text { (2014), Cicchetti and Rogosch (2014) and Little et al. } \\
\text { (2014) }\end{array}$ & Polymorphism & 24 yes/2 no \\
\hline BDNF & $\begin{array}{l}\text { Hilt et al. (2007), Duncan et al. (2009), Goodyer et al. } \\
\text { (2010), Mata et al. (2010), Nederhof et al. (2010), Chen } \\
\text { et al. (2012, 2013), Buchmann et al. (2013), Comasco } \\
\text { et al. (2013), Stavrakakis et al. (2013), Cicchetti and } \\
\text { Rogosch (2014) and Cruz-Fuentes et al. (2014). }\end{array}$ & & \\
\hline FK506 binding protein 5 (FKBP5) gene & Brent et al. (2010) & Polymorphism & yes \\
\hline Estrogen receptor $\alpha, \beta$ & Geng et al. (2007) & Polymorphism & no \\
\hline Androgen receptor (AR) & Geng et al. (2007) & Polymorphism & no \\
\hline Glucocorticoid receptor & Bouma et al. (2011) & Polymorphism & no \\
\hline IL-1 $\beta / \mathrm{IL}-6 / \mathrm{TNF}-\alpha$ & Pandey et al. (2012) & Expression & yes \\
\hline Neurotrophic tyrosine kinase receptor & Feng et al. (2008) & Linkage analysis & yes \\
\hline CREB/CREB1 & Burcescu et al. (2005) and Pandey et al. (2007) & Expression/Polymorphism & yes/no \\
\hline Adipose polyunsaturated fatty acid gene & Mamalakis et al. (2004) & Expression & no \\
\hline CART & Miraglia del Giudice et al. (2006) & Polymorphism & yes \\
\hline OXTR & Thompson et al. (2011) & Polymorphism & yes \\
\hline$A P-2 \beta$ & Nilsson et al. (2009) & Polymorphism & yes \\
\hline HTR2A/2C & Eley et al. (2004) & Polymorphism & yes \\
\hline
\end{tabular}

higher depression scores at age 20 among females with one or two $\mathrm{S}$ alleles of 5-HTT gene (Table 4).

Risk of bias was evaluated for the study design, allocation of control individuals, and quality of assay methods. There was a wide variation in methods and analysis. Most studies did not include age or gender-matched control individuals. Most studies did not provide detailed information about current medical treatment in the full study sample. Most studies did not provide observer-based rating scores of depressive symptom severity.

\section{DISCUSSION}

Studies in twins, families, and populations have revealed the genetic influences on depression (Rice, 2009). Deregulated gene expression and specific functional genetic polymorphisms have been demonstrated to be risk factors of depression or to be associated with the severity of depressive symptoms (Dunn et al., 2011). Numerous studies have confirmed the existence of biological etiology in the development and progression of depression during childhood and adolescence (Dunn et al., 2011; Paus, 2013; Cousins and Goodyer, 2015). However, the published reviews did not summarize the up to date biological findings in only adolescents with defined age ranges. Heterogeneity within study subjects is a main concern for the research in depressive patients because the risk factors for the onset of depression in adolescents and in adults are different. Moreover, the depressive adolescents may experience more psychopathology, behavioral and socioemotional problems than adult-depressive patients (Jaffee et al., 2002). It is therefore important to summarize the biological findings in depressive patients with a defined age range. This study updated the genetic findings in adolescent depression with an age range of 10-19 years defined by WHO as adolescence and 20-25 years as young adult. This study demonstrated that genetic polymorphism or expression of 13 genes was associated, but seven tested genes were not associated with the risk or severity of depression in early adolescence, while the polymorphism of three genes was associated with the risk of depression in late adolesence. This review highlighted the role of several genes or gene families as risk factors 
TABLE 2 | Outcomes of studies on the relationship between 5-HTTLPR and depression in adolescents.

\begin{tabular}{|c|c|c|}
\hline Reference & Sample size & Main outcomes or conclusion \\
\hline Stavrakakis et al. (2013) & 1196 & Adolescents' depressive symptoms are not modified by 5-HTTLPR \\
\hline Nobile et al. (2009) & 607 & Short alleles were associated with higher affective problems scores \\
\hline Kohen et al. (2013) & 192 & The s/l vs. I/I genotype showed greater reduction in depression symptoms \\
\hline Comasco et al. (2013) & 1393 & 5-HTTLPR interacted with unfavorable environment in relation to depressive symptoms \\
\hline Cutuli et al. (2013) & 267 & Positive $G \times E$ effects on depression were found \\
\hline Priess-Groben and Hyde (2013) & 309 & Short allele confers susceptibility to stress for females with depression \\
\hline Jenness et al. (2011) & 200 & 5-HTTLPR predict depressive symptoms \\
\hline Otten and Engels (2013) & 310 & Cannabis use increases the risk of depression only in the presence of 5-HTTLPR short allele genotype \\
\hline Uddin et al. (2011) & 2574 & The sl genotype carriers had less higher depressive symptom score \\
\hline Goodyer et al. (2010) & 401 & $\begin{array}{l}\text { 5-HTTLPR short allele modify the risk of a new depressive episode associated with elevated morning } \\
\text { salivary cortisol }\end{array}$ \\
\hline Benjet et al. (2010) & 78 & Short alleles confers vulnerability to depressive symptoms in girls \\
\hline Goodyer et al. (2009) & 403 & Episode of depression was increased in those with the "s" allele \\
\hline Laucht et al. (2009) & 309 & $\begin{array}{l}\mathrm{LL} \text { genotype of } 5 \text {-HTTLPR displayed significantly higher rates of depressive disorders and more } \\
\text { depressive symptoms }\end{array}$ \\
\hline Sjöberg et al. (2006) & 200 & Females carrying the short 5-HTTLPR allele tend to develop depressive symptoms \\
\hline Nederhof et al. (2010) & 1096 & Interaction between 5-HTTLPR polymorphism and childhood adversities did not predict depression score \\
\hline Cicchetti and Rogosch (2014) & 1096 & $\mathrm{G} \times \mathrm{E}$ interaction of $5-\mathrm{HTTLPR}$ and maltreatment on depression symptoms \\
\hline Little et al. (2014) & 174 & $\begin{array}{l}\text { Structural abnormalities in the left hippocampus may be partly responsible for an indirect association } \\
\text { between } 5 \text {-HTTLPR genotype and depressive illness }\end{array}$ \\
\hline Banducci et al. (2014) & 222 & $\begin{array}{l}\text { Among girls, but not boys, each copy of the s allele of the } 5 \text {-HTTLPR was related to increased depressive } \\
\text { symptoms }\end{array}$ \\
\hline Buchmann et al. (2013) & 259 & The carriers of the BDNF Met and 5-HTTLPR s allele are susceptible to depressive symptoms \\
\hline Oppenheimer et al. (2013) & 241 & $\begin{array}{l}\text { Youth with SS genotype of } 5 \text {-HTTLPR experienced greatest increases in depressive symptoms when } \\
\text { exposed to elevations in materal symptoms }\end{array}$ \\
\hline Petersen et al. (2012) & 436 & $\begin{array}{l}\text { Stress affect adolescents' likelihood of experiencing depressed symptoms when they have a low } \\
\text { serotonin TE (A/Gmodified5-HTTLPR) genotype }\end{array}$ \\
\hline Mata et al. (2010) & 50 & $\begin{array}{l}\text { Girls with homozygous for short } 5 \text {-HTTLPR allele showed stronger association between depressive and } \\
\text { bulimic symptoms the long allele }\end{array}$ \\
\hline Hankin et al. (2011) & 220 & 5-HTTLPR confers susceptibility to depression via stress reactivity \\
\hline Uddin et al. (2010) & 524 & 5 -HTTLPR sl genotype is a risk of depressive symptom in adolescent male \\
\hline Aslund et al. (2009) & 1482 & A GxE interaction effect of 5HTTLPR ss allele was found among girls, not boys \\
\hline Eley et al. (2004) & 377 & A significant genotype-environmental risk interaction for 5HTTLPR in the risk of depression in girls only \\
\hline
\end{tabular}

for the development of depression in adolescents. This study improved our understanding of the etiology of adolescent depression, and also identified 5-HTTLPR and BDNF Val66Met polymorphisms as the most studied biomarkers in adolescent depression.
Low serotonin-receptor levels in the brain have been widely recognized to be a key cause of depression. Polymorphisms of the 5-hydroxytryptamine (serotonin) transporter gene-linked polymorphic region (5-HTTLPR) have been widely demonstrated to be a risk factor for depression

TABLE 3 | Outcomes of studies on the relationship between BDNF and dopaminergic pathway and depression in adolescents.

\begin{tabular}{|c|c|c|}
\hline Reference & Sample size & Main outcomes or conclusion \\
\hline Stavrakakis et al. (2013) & 1196 & Adolescents' depressive symptoms are not modified by BDNF \\
\hline Comasco et al. (2013) & 1393 & Depressive symptoms and depression were more common among carriers of either the Val/Val or Met genotypes \\
\hline Goodyer et al. (2010) & 401 & BDNF (Val66Met) modify the risk of a new depressive episode associated with elevated morning salivary cortisol \\
\hline Chen et al. (2012) & 780 & Interaction between BDNF Val66Met polymorphism and environmental stress on depression was observed \\
\hline Nederhof et al. (2010) & 1096 & $\begin{array}{l}\text { Depression score was not significantly predicted by interaction between BDNF Val66Met polymorphism and } \\
\text { childhood adversities }\end{array}$ \\
\hline Mata et al. (2010) & 82 & BDNF met allele moderate the relation between exercise and depressive symptoms \\
\hline Duncan et al. (2009) & 217 & Val/Val genotype correlated with higher levels of depression symptoms \\
\hline Hilt et al. (2007) & 100 & Val/Val genotype was associated with more depressive symptoms \\
\hline Cicchetti and Rogosch (2014) & 1096 & $\mathrm{G} \times \mathrm{G} \times \mathrm{E}$ interaction of BDNF, 5-HTTLPR/CRHR1 and maltreatment on depression symptoms \\
\hline Cruz-Fuentes et al. (2014) & 246 & Possession of BDNF Met allele was statistically linked with a resilient phenotype of major depression disorder \\
\hline Buchmann et al. (2013) & 259 & The carriers of the BDNF Met and 5-HTTLPR s allele are susceptible to depressive symptoms \\
\hline Chen et al. (2013) & 780 & BDNF Val allele modulates the influence of environmental stress on depression \\
\hline Stavrakakis et al. (2013) & 1196 & Adolescents' depressive symptoms are not modified by COMT \\
\hline Guo and Tillman (2009) & 2286 & DRD2*304/178 and DRD4*379/379 genotype are associated with a level of depressive symptoms \\
\hline Bobadilla et al. (2013) & 1882 & DRD4 polymorphism is linked to comorbid marijuana use and depression \\
\hline
\end{tabular}


TABLE 4 | Summary of literature and outcomes in young adult.

\begin{tabular}{|c|c|c|c|}
\hline Gene & Reference & Measurement & Association with depression \\
\hline OXTR & Thompson et al. (2014) & Polymorphism, $n=441$ & OXTR influences the development of depressive symptoms \\
\hline 5HTTLRP & Starr et al. (2013) & Polymorphism, $n=354$ & S-allele predicts relative increases in probability of depression among boys with low security \\
\hline $5 \mathrm{HTT}$ & Hammen et al. (2010) & Polymorphism, $n=346$ & $\begin{array}{l}\text { Chronic family stress at age } 15 \text { predicted higher depression scores at } 20 \text { among those } \\
\text { females with one or two S alleles }\end{array}$ \\
\hline
\end{tabular}

following adverse life experiences. In this review, a total of 26 articles reported an association between 5-HTTLPR variations and depression in adolescents. About $92.3 \%$ of studies $(n=24)$ identified positive associations of 5-HTTLPR polymorphism with the risk for or susceptibility to depression, new depressive episodes, and more severe depressive symptoms. The most commonly examined polymorphism was the 5-HTTLPR variable number tandem repeat (VNTR), which consists of the $\mathrm{s} / \mathrm{s}$, $\mathrm{s} / \mathrm{l}$, and $1 / 1$ genotypes. In most studies, the short (S) allele or heterozygote genotype carriers $(\mathrm{s} / \mathrm{l})$ of 5 -HTTLPR might experience a greater reduction in depressive symptoms over time compared with adolescents with the 5-HTTLPR 1/1 genotype (Table 2). A recent meta-analysis of the association between the 5-HTTLPR, stress, and the development of depression contained 81 studies with a mean age from 9-77 years. A significant relationship between the short form of the 5-HTTLPR and depression was confirmed ( $p=0.0000009$ ). However, nearly $26 \%$ of the 81 studies failed to show any significant association, and four studies even showed opposite results (Sharpley et al., 2014). Only two studies investigated the 5-HTTLPR polymorphism and the risk of depression in young adults at an age range of 20-25 years. These two studies showed a positive association between 5-HTTLPR S-allele and the increased probability of depression in adolescents (Hammen et al., 2010; Starr et al., 2013). These findings suggest that 5-HTTLPR polymorphism is a risk factor for both early onset and late onset depression.

Tryptophan hydroxylase-2 (TPH2) gene has been acknowledged for many years as the only form of tryptophan hydroxylase (TPH) responsible for the synthesis of serotonin in the brain and peripheral tissues. A recent report suggested that $\mathrm{TPH} 2$ gene expression in the dorsal raphe nuclei of depressed suicidal patients is upregulated [14]. This review included 2 studies on TPH2 in adolescents (Nobile et al., 2009; Stavrakakis et al., 2013). However, adolescents' depressive symptoms are not associated with the gene plasticity index of TPH2 (Stavrakakis et al., 2013). Monoamine oxidase A is a monoamine oxidase encoded by the MAOA gene that preferentially deaminates norepinephrine, epinephrine, serotonin, and dopamine. Studies in adolescents demonstrated that depressive symptoms are not associated with gene plasticity index of the MAOA gene (Stavrakakis et al., 2013), whereas gene $\times$ environment interaction of the 5-HTTLPR was further moderated by MAOA activity level (Nobile et al., 2009).

BDNF is the most abundant neurotrophin in the mammalian central nervous system, and reduced BDNF level in the hippocampus has been revealed to be related to the onset of depression (Bai et al., 2012). A single nucleotide polymorphism (SNP) in the BDNF gene (Val66Met) has been shown to influence the activity of the BDNF protein and cause subsequent memory impairment and harm avoidance (Jiang et al., 2005). A significant interaction between BDNF Val66Met and life stress in depression was widely observed in adults (Hosang et al., 2014). In this review, the BDNF gene is the second most frequently studied gene in adolescents with depression. Two studies on the BDNF gene plasticity index and BDNF level showed controversial outcomes. The depressive symptoms were not associated with gene plasticity index of the BDNF gene in adolescents (Stavrakakis et al., 2013), whereas BDNF mRNA level correlated with symptom improvement in adult patients with depression (Cattaneo et al., 2010). Seven studies investigated the association between BDNF Val66Met polymorphism and adolescent depression. Two studies showed no association between BDNF Val66Met polymorphism and depression score, but 10 studies found significant correlations between BDNF polymorphism and adolescent depression. A recent metaanalysis of the interaction between the BDNF Val66Met polymorphism and stress in depression contained 22 studies with a mean age range from 8.85-65 years. Results showed that the Met allele of BDNF Val66Met significantly moderates the relationship between life stress and depression $(p=0.03$; Hosang et al., 2014). This review only contained three studies with an age range from 9-19 years. Moreover, a meta analysis of genes and suicide in 16 studies showed that hypermethylation of BDNF is associated with individuals that died of suicide (Lockwood et al., 2015). The involvement of genetic polymorphisms in the $B D N F$ gene in peripheral tissues of patients with depression may reflect changes in the BDNF level in their brain. The Val66Met polymorphism has been demonstrated to impair the packaging and secretion of BDNF and subsequently reduces hippocampal volume and impairs memory (Kimpton, 2012; Harrisberger et al., 2015).

Dopamine is a major neurotransmitter in the central nervous system, and dysregulation of the dopaminergicsystem is widely reported in people with depression. The hypofunction of the mesolimbic dopaminergic pathway has been linked to anhedonia, one of the major symptoms of depression (Leggio et al., 2013). Studies that directly link genetic polymorphisms in the dopaminergic pathway to depression are abundant but show inconsistent findings (Lawford et al., 2006). For example, Lawford et al study demonstrated that patients with $D R D 2 * \mathrm{~A} 1 / \mathrm{A} 2$ genotype had significantly higher depression scores compared to those with the $D R D 2^{*} \mathrm{~A} 2 / \mathrm{A} 2$ genotype (Lawford et al., 2006). An interaction between DAT1 polymorphism and perceived maternal rejection can influence the onset of depressive disorder and suicidal ideation (Haeffel et al., 2008). A significant association between the 48 bp repeat 
polymorphism of DRD4 and depression was reported (Manki et al., 1996). In contrast, Frisch et al. (1999) found no association of polymorphisms in DRD4, DAT1, and COMT with depression. Kirov et al. (1999) found that six dopaminergic genes $(D B H$, $D A T 1, C O M T, D R D 2, D R D 3$, and DRD5) played no role in bipolar disorder. However, the roles of genetic polymorphisms in the dopaminergic pathway in adolescent depression have not been summarized. In this study, three studies reported associations between genetic variants in the dopaminergic system and adolescent depression (Bobadilla et al., 2013; Stavrakakis et al., 2013). Significant associations between DRD2, DRD4, and COMT polymorphisms and the risk of depression, as well as the severity of depressive symptoms, were reported.

Selective serotonin reuptake inhibitors (SSRIs) are the first line treatment for depression in the clinic. These inhibitors work by increasing serotonin levels in the brain to counteract the low serotonin-receptor levels. A meta-analysis has demonstrated that the 5-HTTLPR long-allele carriers had higher probability of response than patients with short-allele homozygotes of 5-HTTLPR with heterogeneity effect (Serretti et al., 2007). No study investigated the effect of 5-HTTLPR polymorphism on the efficacy of SSRIs treatment at an age range from 9-19 years. Rotberg et al. (2013) study in 83 children and adolescents aged 7-18 years showed that the 5-HTTLPR ss genotype was associated with a poorer clinical response to citalopram with regards to depressive symptoms. A recent meta analysis showed that the BDNF Met carriers had a better response rate to SSRI than Val/Val, while Met/Val carriers had a weak effect of response to SSRIs than $\mathrm{Val} / \mathrm{Val}$ carriers (Yan et al., 2014). Based on the report from Hammen et al. (2010) study that patients younger than 18 years old have an increased risk of suicidal thoughts or behaviors ( $4 \%$ with SSRIs vs. $2 \%$ with placebo) with an antidepressant (Gordon and Melvin, 2013), FDA suggests that

\section{REFERENCES}

Aslund, C., Leppert, J., Comasco, E., Nordquist, N., Oreland, L., and Nilsson, K. W. (2009). Impact of the interaction between the 5HTTLPR polymorphism and maltreatment on adolescent depression. A population-based study. Behav. Genet. 39, 524-531. doi: 10.1007/s10519-009-9285-9

Bai, M., Zhu, X., Zhang, Y., Zhang, S., Zhang, L., Xue, L., et al. (2012). Abnormal hippocampal BDNF and miR-16 expression is associated with depression-like behaviors induced by stress during early life. PLoS One 7:e46921. doi: 10 . 1371/journal.pone.0046921

Banducci, A. N., Gomes, M., MacPherson, L., Lejuez, C. W., Potenza, M. N., Gelernter, J., et al. (2014). A preliminary examination of the relationship between the 5-HTTLPR and childhood emotional abuse on depressive symptoms in 10-12-year-old youth. Psychol. Trauma 6, 1-7. doi: 10. 1037/a0031121

Benjet, C., Thompson, R. J., and Gotlib, I. H. (2010). 5-HTTLPR moderates the effect of relational peer victimization on depressive symptoms in adolescent girls. J. Child Psychol. Psychiatry 51, 173-179. doi: 10.1111/j.1469-7610.2009. 02149.x

Bobadilla, L., Vaske, J., and Asberg, K. (2013). Dopamine receptor (D4) polymorphism is related to comorbidity between marijuana abuse and depression. Addict. Behav. 38, 2555-2562. doi: 10.1016/j.addbeh.2013. 05.014

Bouma, E. M., Riese, H., Nolte, I. M., Oosterom, E., Verhulst, F. C., Ormel, J., et al. (2011). No associations between single nucleotide polymorphisms in corticoid receptor genes and heart rate and cortisol responses to a standardized social adolescents taking SSRIs must be closely monitored to reduce the risk for suicide. However, the risk is small and the risk hasn't been replicated very well in studies of adolescent depression treated with SSRIs. For example, Hetrick et al. (2012) study showed that no significant increase in suicide-related outcomes was observed in children and adolescents after using individual SSRIs, such as paroxetine, fluoxetine, sertraline, citalopram, and escitalopram.

In conclusion, there are more published positive associations between the genetic polymorphisms in the serotoninergic system, dopaminergic system, and the Val66Met polymorphism of BDNF with adolescent depression. However, some biases should be considered: (1) the publication bias for positive findings; (2) numerous negative findings may be unpublished; (3) a bias for investigations of these three polymorphisms first because of the high profile papers that brought them to attention; and (4) the polymorphisms can be easily genotyped. Although the expression or polymorphism of 18 genes has been reported to be or not be associated with the risk of depression, they were reported by only a few studies. Therefore, further studies are needed to accurately identify their roles in depression in adolescents.

\section{AUTHOR CONTRIBUTIONS}

LX: data extraction, data analysis, and manuscript writing. SY: study design, data extraction, data analysis, critical revision of manuscript, and a guarantor of the review.

\section{FUNDING}

This study is supported by grants from the National Natural Science Foundation of China (81471384 to SY).

stress test in adolescents: the TRAILS study. Behav. Genet. 41, 253-261. doi: 10 1007/s10519-010-9385-6

Brent, D., Melhem, N., Ferrell, R., Emslie, G., Wagner, K. D., Ryan, N., et al. (2010). Association of FKBP5 polymorphisms with suicidal events in the Treatment of Resistant Depression in Adolescents (TORDIA) study. Am. J. Psychiatry 167, 190-197. doi: 10.1176/appi.ajp.2009.09040576

Buchmann, A. F., Hellweg, R., Rietschel, M., Treutlein, J., Witt, S. H., Zimmermann, U. S., et al. (2013). BDNF Val 66 Met and 5-HTTLPR genotype moderate the impact of early psychosocial adversity on plasma brain-derived neurotrophic factor and depressive symptoms: a prospective study. Eur. Neuropsychopharmacol. 23, 902-929. doi: 10.1016/j.euroneuro.2012.09.003

Bufalino, C., Hepgul, N., Aguglia, E., and Pariante, C. M. (2013). The role of immune genes in the association between depression and inflammation: a review of recent clinical studies. Brain Behav. Immun. 31, 31-47. doi: 10.1016/j. bbi.2012.04.009

Burcescu, I., Wigg, K., King, N., Vetró, A., Kiss, E., Katay, L., et al. (2005). Association study of CREB1 and childhood-onset mood disorders. Am. J. Med. Genet. B Neuropsychiatr. Genet. 137B, 45-50. doi: 10.1002/ajmg.b.30201

Cattaneo, A., Bocchio-Chiavetto, L., Zanardini, R., Milanesi, E., Placentino, A., and Gennarelli, M. (2010). Reduced peripheral brain-derived neurotrophic factor mRNA levels are normalized by antidepressant treatment. Int. J. Neuropsychopharmacol. 13, 103-108. doi: 10.1017/S14611457099 90812

Chen, J., Li, X., and McGue, M. (2012). Interacting effect of BDNF Val66Met polymorphism and stressful life events on adolescent depression. Genes Brain Behav. 11, 958-965. doi: 10.1111/j.1601-183x.2012.00843.x 
Chen, J., Li, X., and McGue, M. (2013). The interacting effect of the BDNF Val66Met polymorphism and stressful life events on adolescent depression is not an artifact of gene-environment correlation: evidence from a longitudinal twin study. J. Child Psychol. Psychiatry 54, 1066-1073. doi: 10.1111/jcpp.12099

Cicchetti, D., and Rogosch, F. A. (2014). Genetic moderation of child maltreatment effects on depression and internalizing symptoms by serotonin transporter linked polymorphic region (5-HTTLPR), brain-derived neurotrophic factor (BDNF), norepinephrine transporter (NET) and corticotropin releasing hormone receptor 1 (CRHR1) genes in African American children. Dev. Psychopathol. 26, 1219-1239. doi: 10.1017/s0954579414000984

Comasco, E., Åslund, C., Oreland, L., and Nilsson, K. W. (2013). Three-way interaction effect of 5-HTTLPR, BDNF Val66Met and childhood adversity on depression: a replication study. Eur. Neuropsychopharmacol. 23, 1300-1306. doi: 10.1016/j.euroneuro.2013.01.010

Cousins, L., and Goodyer, I. M. (2015). Antidepressants and the adolescent brain. J. Psychopharmacol. 29, 545-555. doi: 10.1177/0269881115573542

Cruz-Fuentes, C. S., Benjet, C., Martínez-Levy, G. A., Pérez-Molina, A., BrionesVelasco, M., and Suárez-González, J. (2014). BDNF Met66 modulates the cumulative effect of psychosocial childhood adversities on major depression in adolescents. Brain Behav. 4, 290-297. doi: 10.1002/brb3.220

Cutuli, J. J., Raby, K. L., Cicchetti, D., Englund, M. M., and Egeland, B. (2013). Contributions of maltreatment and serotonin transporter genotype to depression in childhood, adolescence and early adulthood. J. Affect. Disord. 149, 30-37. doi: 10.1016/j.jad.2012.08.011

Duncan, L. E., Hutchison, K. E., Carey, G., and Craighead, W. E. (2009). Variation in brain-derived neurotrophic factor (BDNF) gene is associated with symptoms of depression. J. Affect. Disord. 115, 215-219. doi: 10.1016/j.jad.2008.08.016

Dunn, E. C., Uddin, M., Subramanian, S. V., Smoller, J. W., Galea, S., and Koen, K. C. (2011). Research review: gene-environment interaction research in youth depression-a systematic review with recommendations for future research. J. Child Psychol. Psychiatry 52, 1223-1238. doi: 10.1111/j.1469-7610.2011. $02466 . x$

Eley, T. C., Sugden, K., Corsico, A., Gregory, A. M., Sham, P., McGuffin, P., et al. (2004). Gene-environment interaction analysis of serotonin system markers with adolescent depression. Mol. Psychiatry 9, 908-915. doi: 10.1038/sj.mp. 4001546

Feng, Y., Vetró, A., Kiss, E., Kapornai, K., Daróczi, G., Mayer, L., et al. (2008). Association of the neurotrophic tyrosine kinase receptor 3 (NTRK3) gene and childhood-onset mood disorders. Am. J. Psychiatry 165, 610-616. doi: 10. 1176/appi.ajp.2007.07050805

Franić, S., Middeldorp, C. M., Dolan, C. V., Ligthart, L., and Boomsma, D. I. (2010). Childhood and adolescent anxiety and depression: beyond heritability. J. Am. Acad. Child Adolesc. Psychiatry 49, 820-829. doi: 10.1016/j.jaac.2010. 05.013

Frisch, A., Postilnick, D., Rockah, R., Michaelovsky, E., Postilnick, S., Birman, E., et al. (1999). Association of unipolar major depressive disorder with genes of the serotonergic and dopaminergic pathways. Mol. Psychiatry 4, 389-392. doi: $10.1038 /$ s.mp. 4000536

Geng, Y. G., Su, Q. R., Su, L. Y., Chen, Q., Ren, G. Y., Shen, S. Q., et al. (2007). Comparison of the polymorphisms of androgen receptor gene and estrogen alpha and beta gene between adolescent females with first-onset major depressive disorder and controls. Int. J. Neurosci. 117, 539-547. doi: 10. 1080/00207450600773640

Goodyer, I. M., Bacon, A., Ban, M., Croudace, T., and Herbert, J. (2009). Serotonin transporter genotype, morning cortisol and subsequent depression in adolescents. Br. J. Psychiatry 195, 39-45. doi: 10.1192/bjp.bp.108.054775

Goodyer, I. M., Croudace, T., Dudbridge, F., Ban, M., and Herbert, J. (2010). Polymorphisms in BDNF (Val66Met) and 5-HTTLPR, morning cortisol and subsequent depression in at-risk adolescents. Br. J. Psychiatry 197, 365-371. doi: 10.1192/bjp.bp.110.077750

Gordon, M., and Melvin, G. (2013). Selective serotonin re-uptake inhibitors-a review of the side effects in adolescents. Aust. Fam. Physician 42, 620-623.

Guo, G., and Tillman, K. H. (2009). Trajectories of depressive symptoms, dopamine D2 and D4 receptors, family socioeconomic status and social support in adolescence and young adulthood. Psychiatr. Genet. 19, 14-26. doi: 10. 1097/YPG.0b013e32831219b6

Haeffel, G. J., Getchell, M., Koposov, R. A., Yrigollen, C. M., DeYoung, C. G., Klinteberg, B., et al. (2008). Association between polymorphisms in the dopamine transporter gene and depression: evidence for a gene-environment interaction in a sample of juvenile detainees. Psychol. Sci. 19, 62-69. doi: 10. 1111/j.1467-9280.2008.02047.x

Hammen, C., Brennan, P. A., Keenan-Miller, D., Hazel, N. A., and Najman, J. M. (2010). Chronic and acute stress, gender and serotonin transporter geneenvironment interactions predicting depression symptoms in youth. J. Child Psychol. Psychiatry 51, 180-187. doi: 10.1111/j.1469-7610.2009.02177.x

Hankin, B. L., Jenness, J., Abela, J. R., and Smolen, A. (2011). Interaction of 5HTTLPR and idiographic stressors predicts prospective depressive symptoms specifically among youth in a multiwave design. J. Clin. Child Adolesc. Psychol. 40, 572-585. doi: 10.1080/15374416.2011.581613

Harrisberger, F., Smieskova, R., Schmidt, A., Lenz, C., Walter, A., Wittfeld, K., et al. (2015). BDNF Val66Met polymorphism and hippocampal volume in neuropsychiatric disorders: a systematic review and meta-analysis. Neurosci. Biobehav. Rev. 55, 107-118. doi: 10.1016/j.neubiorev.2015.04.017

Hetrick, S. E., McKenzie, J. E., Cox, G. R., Simmons, M. B., and Merry, S. N. (2012). Newer generation antidepressants for depressive disorders in children and adolescents. Cochrane Database Syst. Rev. 11:CD004851. doi: 10. 1002/14651858.CD004851

Hilt, L. M., Sander, L. C., Nolen-Hoeksema, S., and Simen, A. A. (2007). The BDNF Val66Met polymorphism predicts rumination and depression differently in young adolescent girls and their mothers. Neurosci. Lett. 429, 12-16. doi: 10. 1016/j.neulet.2007.09.053

Hosang, G. M., Shiles, C., Tansey, K. E., McGuffin, P., and Uher, R. (2014). Interaction between stress and the BDNF Val66Met polymorphism in depression: a systematic review and meta-analysis. BMC Med. 12:7. doi: 10 1186/1741-7015-12-7

Jaffee, S. R., Moffitt, T. E., Caspi, A., Fombonne, E., Poulton, R., and Martin, J. (2002). Differences in early childhood risk factors for juvenile-onset and adultonset depression. Arch. Gen. Psychiatry 59, 215-222. doi: 10.1001/archpsyc.59. 3.215

Jenness, J. L., Hankin, B. L., Abela, J. R., Young, J. F., and Smolen, A. (2011). Chronic family stress interacts with 5-HTTLPR to predict prospective depressive symptoms among youth. Depress. Anxiety 28, 1074-1080. doi: 10. 1002/da.20904

Jiang, X., Xu, K., Hoberman, J., Tian, F., Marko, A. J., Waheed, J. F., et al. (2005). BDNF variation and mood disorders: a novel functional promoter polymorphism and Val66Met are associated with anxiety but have opposing effects. Neuropsychopharmacology 30, 1353-1361. doi: 10.1038/sj.npp.1300703

Kimpton, J. (2012). The brain derived neurotrophic factor and influences of stress in depression. Psychiatr. Danub. 24, S169-S171.

Kirov, G., Jones, I., McCandless, F., Craddock, N., and Owen, M. J. (1999). Familybased association studies of bipolar disorder with candidate genes involved in dopamine neurotransmission: DBH, DAT1, COMT, DRD2, DRD3 and DRD5. Mol. Psychiatry 4, 558-565. doi: 10.1038/sj.mp.4000565

Kohen, R., Myaing, M. T., Richards, J., Zhou, C., McCauley, E. A., Katon, W., et al. (2013). Depression persistence and serotonin transporter genotype in adolescents under usual care conditions. J. Child Adolesc. Psychopharmacol. 23, 290-294. doi: 10.1089/cap.2011.0137

Laucht, M., Treutlein, J., Blomeyer, D., Buchmann, A. F., Schmid, B., Becker, K., et al. (2009). Interaction between the 5-HTTLPR serotonin transporter polymorphism and environmental adversity for mood and anxiety psychopathology: evidence from a high-risk community sample of young adults. Int. J. Neuropsychopharmacol. 12, 737-747. doi: 10. $1017 /$ s1461145708009875

Lawford, B. R., Young, R., Noble, E. P., Kann, B., and Ritchie, T. (2006). The D2 dopamine receptor (DRD2) gene is associated with co-morbid depression, anxiety and social dysfunction in untreated veterans with post-traumatic stress disorder. Eur. Psychiatry 21, 180-185. doi: 10.1016/j.eurpsy.2005.01.006

Leggio, G. M., Salomone, S., Bucolo, C., Platania, C., Micale, V., Caraci, F., et al. (2013). Dopamine $\mathrm{D}(3)$ receptor as a new pharmacological target for the treatment of depression. Eur. J. Pharmacol. 719, 25-33. doi: 10.1016/j.ejphar. 2013.07.022

Little, K., Olsson, C. A., Whittle, S., Youssef, G. J., Byrne, M. L., Simmons, J. G., et al. (2014). Association between serotonin transporter genotype, brain structure and adolescent-onset major depressive disorder: a longitudinal prospective study. Transl. Psychiatry 4:e445. doi: 10.1038/tp.2014.85

Lockwood, L. E., Su, S., and Youssef, N. A. (2015). The role of epigenetics in depression and suicide: a platform for gene-environment interactions. Psychiatry Res. 228, 235-242. doi: 10.1016/j.psychres.2015.05.071 
Mamalakis, G., Kiriakakis, M., Tsibinos, G., and Kafatos, A. (2004). Depression and adipose polyunsaturated fatty acids in an adolescent group. Prostaglandins Leukot. Essent. Fatty Acids 71, 289-294. doi: 10.1016/j.plefa.2004.04.002

Manki, H., Kanba, S., Muramatsu, T., Higuchi, S., Suzuki, E., Matsushita, S., et al. (1996). Dopamine D2, D3 and D4 receptor and transporter gene polymorphisms and mood disorders. J. Affect. Disord. 40, 7-13. doi: 10. 1016/0165-0327(96)00035-3

Mata, J., and Gotlib, I. H. (2011). 5-HTTLPR moderates the relation between changes in depressive and bulimic symptoms in adolescent girls: a longitudinal study. Int. J. Eat. Disord. 44, 383-388. doi: 10.1002/eat.20850

Mata, J., Thompson, R. J., and Gotlib, I. H. (2010). BDNF genotype moderates the relation between physical activity and depressive symptoms. Health Psychol. 29, 130-133. doi: 10.1037/a0017261

Miraglia del Giudice, E., Santoro, N., Fiumani, P., Dominguez, G., Kuhar, M. J., and Perrone, L. (2006). Adolescents carrying a missense mutation in the CART gene exhibit increased anxiety and depression. Depress. Anxiety 23, 90-92. doi: 10.1002/da.20156

Nederhof, E., Bouma, E. M., Oldehinkel, A. J., and Ormel, J. (2010). Interaction between childhood adversity, brain-derived neurotrophic factor val/met and serotonin transporter promoter polymorphism on depression: the TRAILS study. Biol. Psychiatry 68, 209-212. doi: 10.1016/j.biopsych.2010.04.006

Nilsson, K. W., Sjöberg, R. L., Leppert, J., Oreland, L., and Damberg, M. (2009). Transcription factor AP-2 beta genotype and psychosocial adversity in relation to adolescent depressive symptomatology. J. Neural Transm. Vienna 116, 363-370. doi: 10.1007/s00702-009-0183-3

Nobile, M., Rusconi, M., Bellina, M., Marino, C., Giorda, R., Carlet, O., et al. (2009). The influence of family structure, the TPH2 G-703T and the 5HTTLPR serotonergic genes upon affective problems in children aged 10-14 years. J. Child Psychol. Psychiatry 50, 317-325. doi: 10.1111/j.1469-7610.2008. 01958.x

Oppenheimer, C. W., Hankin, B. L., Young, J. F., and Smolen, A. (2013). Youth genetic vulnerability to maternal depressive symptoms: 5-HTTLPR as moderator of intergenerational transmission effects in a multiwave prospective study. Depress. Anxiety 30, 190-196. doi: 10.1002/da.22056

Otten, R., and Engels, R. C. (2013). Testing bidirectional effects between cannabis use and depressive symptoms: moderation by the serotonin transporter gene. Addict. Biol. 18, 826-835. doi: 10.1111/j.1369-1600.2011.00380.x

Pandey, G. N., Dwivedi, Y., Ren, X., Rizavi, H. S., Roberts, R. C., and Conley, R. R. (2007). Cyclic AMP response element-binding protein in post-mortem brain of teenage suicide victims: specific decrease in the prefrontal cortex but not the hippocampus. Int. J. Neuropsychopharmacol. 10, 621-629. doi: 10. $1017 /$ s1461145706007231

Pandey, G. N., Rizavi, H. S., Ren, X., Fareed, J., Hoppensteadt, D. A., Roberts, R. C., et al. (2012). Proinflammatory cytokines in the prefrontal cortex of teenage suicide victims. J. Psychiatr. Res. 46, 57-63. doi: 10.1016/j.jpsychires.2011. 08.006

Paus, T. (2013). How environment and genes shape the adolescent brain. Horm. Behav. 64, 195-202. doi: 10.1016/j.yhbeh.2013.04.004

Petersen, I. T., Bates, J. E., Goodnight, J. A., Dodge, K. A., Lansford, J. E., and Pettit, G. S. (2012). Interaction between serotonin transporter polymorphism (5-HTTLPR) and stressful life events in adolescents' trajectories of anxious/depressed symptoms. Dev. Psychol. 48, 1463-1475. doi: 10. 1037/a0027471

Priess-Groben, H. A., and Hyde, J. S. (2013). 5-HTTLPR X stress in adolescent depression: moderation by MAOA and gender. J. Abnorm. Child Psychol. 41, 281-294. doi: 10.1007/s10802-012-9672-1

Rice, F. (2009). The genetics of depression in childhood and adolescence. Curr. Psychiatry Rep. 11, 167-173. doi: 10.1007/s11920-009-0026-9

Rice, F. (2010). Genetics of childhood and adolescent depression: insights into etiological heterogeneity and challenges for future genomic research. Genome Med. 2:68. doi: 10.1186/gm189

Rotberg, B., Kronenberg, S., Carmel, M., Frisch, A., Brent, D., Zalsman, G., et al. (2013). Additive effects of 5-HTTLPR (serotonin transporter) and tryptophan hydroxylase 2 G-703T gene polymorphisms on the clinical response to citalopram among children and adolescents with depression and anxiety disorders. J. Child Adolesc. Psychopharmacol. 23, 117-122. doi: 10.1089/cap. 2012.0020

Serretti, A., Kato, M., De Ronchi, D., and Kinoshita, T. (2007). Meta-analysis of serotonin transporter gene promoter polymorphism (5-HTTLPR) association with selective serotonin reuptake inhibitor efficacy in depressed patients. Mol. Psychiatry 12, 247-257. doi: 10.1038/sj.mp.4001926

Sharpley, C. F., Palanisamy, S. K., Glyde, N. S., Dillingham, P. W., and Agnew, L. L. (2014). An update on the interaction between the serotonin transporter promoter variant (5-HTTLPR), stress and depression, plus an exploration of non-confirming findings. Behav. Brain Res. 273, 89-105. doi: 10.1016/j.bbr. 2014.07.030

Sjöberg, R. L., Nilsson, K. W., Nordquist, N., Ohrvik, J., Leppert, J., Lindström, L., et al. (2006). Development of depression: sex and the interaction between environment and a promoter polymorphism of the serotonin transporter gene. Int. J. Neuropsychopharmacol. 9, 443-449. doi: 10.1017/s1461145705005936

Starr, L. R., Hammen, C., Brennan, P. A., and Najman, J. M. (2013). Relational security moderates the effect of serotonin transporter gene polymorphism (5HTTLPR) on stress generation and depression among adolescents. J. Abnorm. Child Psychol. 41, 379-388. doi: 10.1007/s10802-012-9682-z

Stavrakakis, N., Oldehinkel, A. J., Nederhof, E., Oude Voshaar, R. C., Verhulst, F. C., Ormel, J., et al. (2013). Plasticity genes do not modify associations between physical activity and depressive symptoms. Health Psychol. 32, 785-792. doi: 10.1037/a0030111

Thompson, S. M., Hammen, C., Starr, L. R., and Najman, J. M. (2014). Oxytocin receptor gene polymorphism (rs53576) moderates the intergenerational transmission of depression. Psychoneuroendocrinology 43, 11-19. doi: 10. 1016/j.psyneuen.2014.01.012

Thompson, R. J., Parker, K. J., Hallmayer, J. F., Waugh, C. E., and Gotlib, I. H. (2011). Oxytocin receptor gene polymorphism (rs2254298) interacts with familial risk for psychopathology to predict symptoms of depression and anxiety in adolescent girls. Psychoneuroendocrinology 36, 144-147. doi: 10 1016/j.psyneuen.2010.07.003

Uddin, M., de los Santos, R., Bakshis, E., Cheng, C., and Aiello, A. E. (2011). Building conditions, 5-HTTLPR genotype and depressive symptoms in adolescent males and females. J. Adolesc. Health 49, 379-385. doi: 10.1016/j. jadohealth.2011.01.013

Uddin, M., Koenen, K. C., de Los Santos, R., Bakshis, E., Aiello, A. E., and Galea, S. (2010). Gender differences in the genetic and environmental determinants of adolescent depression. Depress. Anxiety 27, 658-666. doi: 10.1002/da.20692

WHO (2014a). Depression-world health organization. Available online at: http:// www.who.int/mediacentre/factsheets/fs369/en/ (accessed October 32015 ).

WHO (2014b). Adolescent health. Available online at: http://www.who.int/topics/ adolescent_health/en/ (accessed October 32015 ).

WHO EMRO (2014). World mental health. http://www.emro.who.int/media/news /mental-health-day2012.html (accessed October 10 2012).

Yan, T., Wang, L., Kuang, W., Xu, J., Li, S., Chen, J., et al. (2014). Brain-derived neurotrophic factor Val66Met polymorphism association with antidepressant efficacy: a systematic review and meta-analysis. Asia Pac. Psychiatry 6, 241-251. doi: 10.1111/appy.12148

Zhang, W., Cao, Y., Wang, M., Ji, L., Chen, L., and Deater-Deckard, K. (2015). The dopamine D2 receptor Polymorphism (DRD2 TaqIA) interacts with maternal parenting in predicting early adolescent depressive symptoms: evidence of differential susceptibility and age differences. J. Youth Adolesc. 44, 1428-1440. doi: 10.1007/s10964-015-0297-x

Conflict of Interest Statement: The authors declare that the research was conducted in the absence of any commercial or financial relationships that could be construed as a potential conflict of interest.

Copyright (C) 2015 Xia and Yao. This is an open-access article distributed under the terms of the Creative Commons Attribution License (CC BY). The use, distribution and reproduction in other forums is permitted, provided the original author(s) or licensor are credited and that the original publication in this journal is cited, in accordance with accepted academic practice. No use, distribution or reproduction is permitted which does not comply with these terms. 